\title{
Improving Pesticide Uptake Modeling into Potatoes: Considering Tuber Growth Dynamics
}

\author{
Xiao, Shenglan; Gong, Yishu; Li, Zijian; Fantke, Peter
}

Published in:

Journal of Agricultural and Food Chemistry

Link to article, DOI:

10.1021/acs.jafc.1c00151

Publication date:

2021

Document Version

Publisher's PDF, also known as Version of record

Link back to DTU Orbit

Citation (APA):

Xiao, S., Gong, Y., Li, Z., \& Fantke, P. (2021). Improving Pesticide Uptake Modeling into Potatoes: Considering Tuber Growth Dynamics. Journal of Agricultural and Food Chemistry, 69(12), 3607-3616.

https://doi.org/10.1021/acs.jafc.1c00151

\section{General rights}

Copyright and moral rights for the publications made accessible in the public portal are retained by the authors and/or other copyright owners and it is a condition of accessing publications that users recognise and abide by the legal requirements associated with these rights.

- Users may download and print one copy of any publication from the public portal for the purpose of private study or research.

- You may not further distribute the material or use it for any profit-making activity or commercial gain

- You may freely distribute the URL identifying the publication in the public portal

If you believe that this document breaches copyright please contact us providing details, and we will remove access to the work immediately and investigate your claim. 


\title{
Improving Pesticide Uptake Modeling into Potatoes: Considering Tuber Growth Dynamics
}

\author{
Shenglan Xiao, Yishu Gong, Zijian Li,* and Peter Fantke
}

Cite This: J. Agric. Food Chem. 2021, 69, 3607-3616

Read Online

ABSTRACT: To explore pesticide uptake from soil into a growing potato, a moving-boundary dynamic model is proposed on the basis of the radical diffusion process of a chemical to a sphere. This model, which considers the logistic growth of the potato tuber, describes two hypothetical processes of chemical diffusion within a growing tuber. The model was tested in an illustrative case study for an application of chlorpyrifos. Results indicate that the distribution of chlorpyrifos concentrations along the potato radius is significantly affected by the tuber development. In comparison of our results to results from a classic model using a fixed boundary, the proposed dynamic model yields a quick and big jump for both the average concentration and bioconcentration factor (BCF) of chlorpyrifos in the potato as a result of the sigmoid expansion boundary. Overall, the dynamic model predicts that chlorpyrifos BCFs in the potato at harvest are higher than those using the classical model. In comparison of model results to measured uptake of chlorpyrifos into potato at harvest, the dynamic model shows better performance than the classical model. Our results provide a new perspective on pesticide uptake into potatoes and inform human health risk assessment for pesticides applied at different tuber growth stages.

KEYWORDS: uptake model, soil pollution, crop contaminations, diffusion process, logistic growth

\section{INTRODUCTION}

Pesticides are widely used in agricultural fields to protect crops against pests, insects, and weeds. ${ }^{1,2}$ After application, pesticide residues can be emitted and transported into various environmental media, including air, soils, water, and crops, ${ }^{3}$ and can cause human and ecological health damages. ${ }^{4,5}$ Among possible human exposure pathways, pesticide residues in crops grown for human consumption usually dominate overall exposure for the general population. ${ }^{6,7}$ In addition to field sampling and analytical detection, modeling the plant uptake of pesticide residues can be an efficient way for high-throughput estimation of residual pesticide concentrations. Previous modeling studies have made extensive efforts to predict the residue concentrations in plants for various uptake scenarios, including soil-based uptake ${ }^{8-10}$ (e.g., into grasses), spray-based absorption $^{11}$ (e.g., into tomatoes), diffusion-based uptake ${ }^{12,13}$ (e.g., into potatoes), and multi-pathway uptake ${ }^{14-18}$ (e.g., into wheat and tomato).

Potato, as the most widely consumed root and tuber crop, plays a significant role in the global food security, because potatoes can be easily grown and yield high production rates. ${ }^{19}$ However, pesticides and other chemical contaminants have been widely detected in potatoes, ${ }^{20,21}$ which has become a major population health concern. Diffusion processes play a significant role in the chemical bioaccumulation of pesticides in potatoes from surrounding soils. ${ }^{12-14,22}$ The chemical concentration gradient between the soil, to which several pesticides are directly applied, and potato tissues thermodynamically drives chemicals toward uptake into the potato tubers. To understand this process, modeling studies have made great efforts to predict the bioconcentration of chemicals in potatoes. For example, Trapp et al. ${ }^{12}$ developed a diffusion model for carrots and potatoes and evaluated the model by combining it with disc experiments. Paraiba and Kataguiri ${ }^{23}$ simulated the bioconcentration factor (BCF) of pesticides in potatoes by evaluating the fate of pesticides in soil solutions and potatoes. Juraske et al. ${ }^{13}$ integrated the pesticide application patterns into a diffusion model to provide a realistic perspective of pesticides applied to agricultural fields. Fantke et al. ${ }^{14,24}$ developed a multi-crop model, which generalizes the chemical transport of pesticides into various crops (e.g., apple and potato) based on coupling different fate processes via matrix algebra. ${ }^{15}$

All of these models build on a classic diffusion model, focusing on the total mass of the chemical entering the potato tubers (or the average concentration in the tubers) and treating the potato as a single box compartment. ${ }^{12,13,23,24}$ This suggests a homogeneous distribution of chemicals throughout the potato tuber, simulating the chemical diffusion process using a fixed boundary between the soil and potato compartments. However, the chemical rather follows a heterogeneous distribution along the radius of the potato tuber (of assumed spherical shape) and is further influenced by the growth of the tuber. The classic diffusion model introduces a "dilution rate" of the chemical in the tuber that is based on

Received: January 9, 2021

Revised: February 22, 2021

Accepted: March 8, 2021

Published: March 17, 2021 
the specific growth rate of the tuber. ${ }^{12,13,23,24}$ This is in line with the assumption of a homogeneous chemical distribution in the tuber. However, the heterogeneous distribution of a chemical along the potato radius could be significantly affected by the expanding boundary of the diffusion process as a result of the growth of the potato, especially during the tuber development stage, where the potato is rapidly growing. This might influence predicted bioaccumulation and pesticide residue results in harvested potato tubers for chemicals that are applied at different times before potato harvest. ${ }^{13}$ This, in turn, is an important aspect to inform the assessment of human exposure and health risks associated with pesticide residues in potato crops. ${ }^{25,26}$

To address this aspect, the present study aims to develop a moving-boundary dynamic model for the uptake of pesticides from soil into potato tubers, with focus on three specific objectives: (1) to evaluate the heterogeneous distribution of chemical concentrations in a growing potato tuber, (2) to simulate the average concentration of a chemical in a wholepotato unit using the integral form of the dynamic model to investigate the uptake process of a chemical as a function of time, and (3) to discuss implications of model assumptions for assessing human exposure and related health risk by comparing our results to results from a classic diffusion model.

\section{METHODS}

2.1. General Modeling Framework. Our study includes three main parts: (1) the partial-differential-equation (PDE)-based model with moving boundary (or dynamic sphere model), (2) the integral form of the dynamic model used to obtain the average concentration of a chemical in potato tubers, and (3) the comparison of our simulated results to those of a classic diffusion model. In the dynamic sphere model, chemical diffusion is assumed to occur along the radius of the considered sphere and a logistic function is applied to describe the expansion of the sphere, which mimics the diffusion process of a pesticide from the soil into a growing potato tuber. The dynamic sphere model was developed using a PDE that describes the chemical concentration as a function of the radius, time, and moving boundary of the sphere, which simulates the heterogeneous distribution of a chemical in a growing potato tuber. We follow a similar approach to simulate chemical uptake into crops as proposed by Satchivi et al. ${ }^{27}$ Next, we obtained numerical solutions to solve the dynamic sphere model (MATLAB, version R2020b). For the integral form of the dynamic sphere model, we integrated the chemical concentration along the radius of the assumed sphere to calculate the total mass of the chemical that has diffused into the growing potato tuber as a function of time. Chemical concentration results were finally compared to results from the classic model for given time steps until tuber harvest. In both dynamic and classic models, the potato peel was not considered separately to simplify the simulation process.

2.2. Classic Diffusion Model. Previous studies adopted a practical approach that treats the absorption of a chemical in a potato as a two-compartment system with a fixed boundary. ${ }^{12,23}$ This approach infers the diffusion of a chemical from soil to potato tissues without characterizing the change of the potato radius, using the constant growth rate of the potato tuber $\left(k_{g}\right.$, day $\left.{ }^{-1}\right)$. Following this approach, diffusion can be expressed until the maximum mass is reached at harvest time $\left(t_{\mathrm{h}}\right.$, day)

$$
\frac{\mathrm{d} C_{\mathrm{P}}^{\mathrm{c}}(t)}{\mathrm{d} t}=\left\{\begin{array}{c}
0 ; 0 \leq t<t_{\mathrm{e}} \\
\underset{\substack{\mathrm{e}}}{-\left(\frac{23 \theta_{\mathrm{W}} T_{\mathrm{P}} D_{\mathrm{W}}}{r^{2} \rho_{\mathrm{P}}}\right)\left(\frac{C_{\mathrm{P}}^{\mathrm{c}}(t)}{K_{\mathrm{PW}}}-\frac{C_{\mathrm{S}}(t)}{K_{\mathrm{SW}}}\right)-\left(k_{\mathrm{g}}+k_{\mathrm{d}, \mathrm{P}}\right) C_{\mathrm{P}}^{\mathrm{c}}(t) ; t}
\end{array}\right.
$$

$$
C_{\mathrm{S}}(t)=\left\{\begin{array}{c}
0 ; 0 \leq t<t_{\mathrm{e}} \\
C_{\mathrm{S}}\left(t_{\mathrm{e}}\right) \exp \left(-k_{\mathrm{d}, \mathrm{S}}\left(t-t_{\mathrm{e}}\right)\right) ; t \geq t_{\mathrm{e}}
\end{array}\right.
$$

where $C_{\mathrm{P}}^{\mathrm{c}}(t)\left(\mathrm{mg} \mathrm{kg}^{-1}\right)$ is the concentration of the chemical simulated by the classic diffusion model. We define $t=0$ as the time at which the potato is seeded or planted and $t_{\mathrm{e}}(\mathrm{d})$ as the time at which a chemical is emitted or applied to soil. $C_{S}(t)\left(\mathrm{mg} \mathrm{kg}^{-1}\right)$ is the concentration of a chemical in the soil, and $K_{\mathrm{PW}}\left(\mathrm{L} \mathrm{kg}^{-1}\right)$ and $K_{\mathrm{SW}}(\mathrm{L}$ $\mathrm{kg}^{-1}$ ) denote the potato-water and bulk soil-water partition coefficients, respectively. $\theta_{\mathrm{W}}\left(\mathrm{g} \mathrm{g}^{-1}\right)$ is the water content of the potato tissue; $T_{\mathrm{P}}$ (dimensionless) is the tortuosity factor of the potato tissue; $D_{\mathrm{W}}\left(\mathrm{m}^{2}\right.$ day $\left.^{-1}\right)$ is the diffusivity of the chemical in water; $\rho_{\mathrm{P}}$ $\left(\mathrm{kg} \mathrm{L}^{-1}\right)$ is the density of the potato tuber; and $C_{\mathrm{S}}\left(t_{\mathrm{e}}\right)$ is the concentration of the chemical in bulk soil immediately after chemical emission or application. $k_{\mathrm{g}}\left(\mathrm{d}^{-1}\right)$ is the specific dilution rate of the chemical concentration in the potato caused by the growth of the potato. $k_{\mathrm{d}, \mathrm{P}}\left(\mathrm{day}^{-1}\right)$ is the degradation rate of the chemical in the potato, including microbial and chemical degradations. We note that several previous studies did not include the degradation process of the chemical in potato tissues based on a conservative assumption commonly applied in human risk assessment. ${ }^{12,23}$ However, our study aims to develop a mass balance model such that all relevant processes in the system are considered, including degradation that competes with diffusion of the chemical from or to soil. ${ }^{28}$ We assumed that the concentration of the chemical in the soil $\left[C_{S}(t), \mathrm{mg} \mathrm{kg}^{-1}\right]$ surrounding the potato is only affected by a first-order degradation process $\left(k_{\mathrm{d}, \mathrm{S}}\right.$, day $\left.^{-1}\right)$. With that, eq 1 can be solved as

$$
C_{\mathrm{P}}^{\mathrm{c}}(t)=\left\{\begin{array}{c}
0 ; 0 \leq t<t_{\mathrm{e}} \\
C_{\mathrm{S}}(0)\left(\frac{k_{\mathrm{S} \rightarrow \mathrm{P}}}{k_{\mathrm{P} \rightarrow \mathrm{S}}+k_{\mathrm{g}}+k_{\mathrm{d}, \mathrm{P}}-k_{\mathrm{d}, \mathrm{S}}}\right)\left[\exp \left(-k_{\mathrm{d}, \mathrm{S}}\left(t-t_{\mathrm{e}}\right)\right)\right. \\
\left.-\exp \left(-\left(k_{\mathrm{P} \rightarrow \mathrm{S}}+k_{\mathrm{g}}+k_{\mathrm{d}, \mathrm{P}}\right)\left(t-t_{\mathrm{e}}\right)\right)\right] ; t \geq t_{\mathrm{e}}
\end{array}\right.
$$

where $k_{\mathrm{S} \rightarrow \mathrm{P}}=\left(23 \theta_{\mathrm{W}} T_{\mathrm{P}} D_{\mathrm{W}}\right) /\left(r^{2} \rho_{\mathrm{P}} K_{\mathrm{SW}}\right)$ and $k_{\mathrm{P} \rightarrow \mathrm{S}}=\left(23 \theta_{\mathrm{W}} T_{\mathrm{P}} D_{\mathrm{W}}\right) /$ $\left(r^{2} \rho_{\mathrm{P}} K_{\mathrm{PW}}\right) . k_{\mathrm{S} \rightarrow \mathrm{P}}\left(\mathrm{day}^{-1}\right)$ and $k_{\mathrm{P} \rightarrow \mathrm{S}}\left(\mathrm{day}^{-1}\right)$ are the specific uptake rate of the chemical from soil into the potato tuber and the specific elimination rate of the chemical back from the potato tuber to the soil, respectively. The related bioconcentration factor simulated from the classic diffusion model $\left[\mathrm{BCF}^{\mathrm{c}}(t), \mathrm{kg} \mathrm{kg}^{-1}\right]$ can be expressed as

$$
\begin{aligned}
& \operatorname{BCF}^{\mathrm{c}}(t) \equiv \frac{C_{\mathrm{P}}^{\mathrm{c}}(t)}{C_{\mathrm{S}}(t)} \\
& =\left\{\begin{array}{c}
\mathrm{NA} ; 0 \leq t<t_{\mathrm{e}} \\
\left(\begin{array}{c}
\left.\frac{k_{\mathrm{S} \rightarrow \mathrm{P}}}{k_{\mathrm{P} \rightarrow \mathrm{S}}+k_{\mathrm{g}}+k_{\mathrm{d}, \mathrm{P}}-k_{\mathrm{d}, \mathrm{S}}}\right) \\
{\left[1-\exp \left(\left(k_{\mathrm{d}, \mathrm{S}}-k_{\mathrm{P} \rightarrow \mathrm{S}}-k_{\mathrm{g}}-k_{\mathrm{d}, \mathrm{P}}\right)\left(t-t_{\mathrm{e}}\right)\right)\right] ; t \geq t_{\mathrm{e}}}
\end{array}\right.
\end{array}\right.
\end{aligned}
$$

Here, $\mathrm{BCF}^{\mathrm{c}}(t)$ is defined as a function of time, i.e., a dynamic function instead of a steady-state ratio derived in previous studies. ${ }^{12,23}$

2.3. Moving-Boundary Dynamic Diffusion Model. Because the mass of various crops, including potatoes, follows a logistic growth function, ${ }^{14,29}$ the uptake process of the chemical from the soil could be affected, especially during the rapid expansion phase of the potato tuber. To reflect this aspect, we developed a moving-boundary dynamic model based on the logistic growth of the potato. The diffusion of a chemical into an assumed potato tuber sphere driven by the concentration differential, i.e., passive diffusion, can be expressed by a basic radial diffusion model

$$
\begin{aligned}
\frac{\partial C_{\mathrm{p}}(r, t)}{\partial t}=0 ; 0 \leq t<t_{\mathrm{e}} ; 0 \leq r \leq r_{\mathrm{p}}(t) \\
\frac{\partial C_{\mathrm{p}}(r, t)}{\partial t}=D_{\mathrm{p}}^{\mathrm{E}}\left(\frac{\partial^{2} C_{\mathrm{p}}(r, t)}{\partial r^{2}}+\frac{2}{r} \frac{\partial C_{\mathrm{p}}(r, t)}{\partial r}\right)-k_{\mathrm{d}, \mathrm{P}} C_{\mathrm{p}}(r, t) ; t \\
\geq t_{\mathrm{e}} ; \quad 0 \leq r \leq r_{\mathrm{p}}(t)
\end{aligned}
$$


Table 1. Summary of the $k_{\mathrm{d}, \mathrm{P}}$ and $k_{\mathrm{d}, \mathrm{S}}$ Values of the Selected Pesticides

\begin{tabular}{|c|c|c|c|c|c|c|}
\hline chemical & compartment & $t_{1 / 2, \mathrm{P}}$ (day) & mean of $t_{1 / 2, \mathrm{P}}$ (day) & $k_{\mathrm{d}, \mathrm{P}}\left(\mathrm{day}^{-1}\right)$ & $k_{\mathrm{d}, \mathrm{S}}\left(\mathrm{day}^{-1}\right)^{a}$ & reference \\
\hline aldicarb & flesh & 5.9 & 5.90 & 0.12 & 0.35 & 32 \\
\hline bendiocarb & flesh & 4.9 & 4.90 & 0.14 & 0.20 & 32 \\
\hline carbaryl & flesh & 4.4 & 4.40 & 0.16 & 0.04 & 32 \\
\hline cymoxanil & tuber & 1.08 & 1.19 & 0.58 & 0.20 & 33 \\
\hline cymoxanil & & 1.3 & & & & \\
\hline ethylenethiourea & tuber & 6.16 & 6.66 & 0.10 & 0.17 & 34 \\
\hline ethylenethiourea & & 7.15 & & & & \\
\hline mancozeb & tuber & 6.41 & 7.15 & 0.10 & 0.04 & 34 \\
\hline mancozeb & & 7.89 & & & & \\
\hline pirimicarb & flesh & 5.9 & 5.90 & 0.12 & 0.08 & 32 \\
\hline propineb & tuber & 2.7 & 3.02 & 0.23 & 0.23 & 35 \\
\hline propineb & & 2.59 & & & & \\
\hline propineb & & 3.09 & & & & \\
\hline propineb & & 3.46 & & & & \\
\hline propineb & & 2.86 & & & & \\
\hline propineb & & 2.67 & & & & \\
\hline propineb & & 3.29 & & & & \\
\hline propineb & & 3.48 & & & & \\
\hline
\end{tabular}

where $C_{\mathrm{p}}(r, t)\left(\mathrm{mg} \mathrm{kg}^{-1}\right)$ is the concentration of the chemical in the potato tuber as a function of time $(t$, day) and distance to the center of the tuber sphere $(r, \mathrm{~m})$. In this model, we define $t=0$ as the time that the potato is seeded with an initial mass of a seedling $\left(M_{\mathrm{p}}^{0}, \mathrm{~kg}\right)$. When the chemical has not yet been emitted or applied to soil $(0 \leq t$ $\left.<t_{\mathrm{e}}\right), C_{\mathrm{p}}(r, t)$ is 0 , such that $\left[\partial C_{\mathrm{p}}(r, t)\right] /(\partial \mathrm{t})=0$. Further, $r_{\mathrm{p}}(t)(\mathrm{m})$ is the radius of the growing potato as a function of time. We assumed that the chemical diffusion process only occurs in the water phase of the soil and the potato tissue, and thus, $D_{\mathrm{p}}^{\mathrm{E}}$, which is the adjusted diffusivity of the chemical in the potato tissue, can be converted from the diffusivity of the chemical in water to $\left(\theta_{\mathrm{W}} T_{\mathrm{P}} D_{\mathrm{W}}\right) /\left(\rho_{\mathrm{P}} K_{\mathrm{PW}}\right){ }^{12,23}$

In a dynamic system, we assume that the growth rate of the mass of a potato $\left[M_{\mathrm{p}}(t), \mathrm{kg}\right]$ follows a logistic function, where $r_{\mathrm{p}}(t)$ is expressed as a function of time $\mathrm{e}^{14,29}$

$$
\begin{aligned}
& M_{\mathrm{p}}(t)=\frac{4}{3} \pi C F \rho_{\mathrm{p}} r_{\mathrm{p}}^{3}(t)=\frac{M_{\mathrm{p}}^{\max }}{1+\left(\frac{M_{\mathrm{p}}^{\max }-M_{\mathrm{p}}^{0}}{M_{\mathrm{p}}^{0}}\right) \exp \left(-k_{\mathrm{g}} t\right)} \\
& r_{\mathrm{p}}(t)=\left(\frac{3 M_{\mathrm{p}}^{\max }}{4 \pi \rho_{\mathrm{p}} C F}\right)^{1 / 3}\left(1+\left(\frac{M_{\mathrm{p}}^{\max }-M_{\mathrm{p}}^{0}}{M_{\mathrm{p}}^{0}}\right) \exp \left(-k_{\mathrm{g}} t\right)\right)^{-1 / 3}
\end{aligned}
$$

where $C F\left(1000 \mathrm{~L} \mathrm{~m}^{-3}\right)$ is a unit conversion factor and $M_{\mathrm{p}}^{\max }(\mathrm{kg})$ is the maximum mass of the potato tuber $\left(t=t_{\mathrm{g}}\right)$. Thus, according to eqs $6 \mathrm{a}$ and $6 \mathrm{~b}$, we can determine $M_{\mathrm{p}}\left(t_{\mathrm{e}}\right)(\mathrm{kg})$ and $r_{\mathrm{p}}\left(t_{\mathrm{e}}\right)(\mathrm{m})$ at the time when the chemical is emitted or applied to soil. At $t=0$, we assumed that the potato tuber has an initial radius of $r_{\mathrm{p}}(0)=\left[\left(3 M_{\mathrm{p}}^{0}\right) /\right.$ $\left.\left(4 \pi \rho_{\mathrm{p}}\right)\right]^{1 / 3}$.

In addition, it was assumed that, at the surface of the potato, the thermodynamic condition of the chemical between the soil and potato tissue can be expressed as follows:

$$
C_{\mathrm{p}}\left(r_{\mathrm{p}}(t), t\right)=\left(\frac{K_{\mathrm{PW}}}{K_{\mathrm{SW}}}\right) C_{\mathrm{S}}(t)
$$

Therefore, the boundary condition at $t=t_{\mathrm{e}}$ can be described as

$$
C\left(r, t_{\mathrm{e}}\right)=\left\{\begin{array}{c}
0 ; r<\left(\frac{3 M_{\mathrm{p}}\left(t_{\mathrm{e}}\right)}{4 \pi \rho_{\mathrm{p}} C F}\right)^{1 / 3} \text { inside potato } \\
\left(\frac{K_{\mathrm{PW}}}{K_{\mathrm{SW}}}\right) C_{\mathrm{S}}(0) ; r=\left(\frac{3 M_{\mathrm{p}}\left(t_{\mathrm{e}}\right)}{4 \pi \rho_{\mathrm{p}} C F}\right)^{1 / 3} \text { potato surface } \\
C_{\mathrm{S}}(0) ; r>\left(\frac{3 M_{\mathrm{p}}\left(t_{\mathrm{e}}\right)}{4 \pi \rho_{\mathrm{p}} C F}\right)^{1 / 3} \text { outside potato }
\end{array}\right.
$$

where $C\left(r, t_{\mathrm{e}}\right)\left(\mathrm{mg} \mathrm{kg}^{-1}\right)$ denotes the concentration of the chemical in the potato tissue at a distance $r$ away from the center of the potato when $t=t_{\mathrm{e}}$. Thus, the entire dynamic sphere model can be expressed as follows:

$$
C(r, t)=0 ; 0 \leq t<t_{\mathrm{e}}
$$

$$
C(r, t)=\left\{\begin{array}{c}
C_{\mathrm{P}}(r, t) ; \quad r<r_{\mathrm{p}}(t) \text { inside potato } \\
\left(\frac{K_{\mathrm{PW}}}{K_{\mathrm{SW}}}\right) C_{\mathrm{S}}(t) ; r=r_{\mathrm{p}}(t) \text { potato surface; } t \geq t_{\mathrm{e}} \\
C_{\mathrm{S}}(t) ; \quad r>r_{\mathrm{p}}(t) \text { outside potato }
\end{array}\right.
$$

$$
r_{\mathrm{p}}(t)=\left(\frac{3 M_{\mathrm{p}}^{\max }}{4 \pi \rho_{\mathrm{p}} C F}\right)^{1 / 3}\left(1+\left(\frac{M_{\mathrm{p}}^{\max }-M_{\mathrm{p}}^{0}}{M_{\mathrm{p}}^{0}}\right) \exp \left(-k_{\mathrm{g}} t\right)\right)^{-1 / 3}
$$

2.4. Diffusion Mass and Average Concentration of Chemicals in Potato. As input for human exposure and health risk assessment, it is important to know the total mass of the chemical (e.g., field-applied agricultural pesticides) that diffuses into the edible potato parts as a function of any given crop harvest time. The total mass of a chemical $\left[M_{\mathrm{C}}(t), \mathrm{mg}\right]$ and its average concentration $\left[\bar{C}_{\mathrm{p}}(t)\right.$, $\left.\mathrm{mg} \mathrm{kg}{ }^{-1}\right]$ in a potato as a function of time can be expressed as

$$
M_{\mathrm{C}}(t)=\left\{\begin{array}{c}
0 ; 0 \leq t<t_{\mathrm{e}} \\
4 \pi \rho_{\mathrm{p}} C F \int_{0}^{r_{\mathrm{p}}(t)} r^{2} C_{\mathrm{p}}(r, t) \mathrm{d} r ; t \geq t_{\mathrm{e}}
\end{array}\right.
$$


Table 2. Model Input Parameters Used for Illustrating the Uptake Process of Chlorpyrifos by a Growing Potato

\begin{tabular}{|c|c|c|c|c|c|}
\hline model input variable & symbol & unit & value & note & reference \\
\hline initial radius & & $\mathrm{m}$ & 0.006 & estimated from the initial mass & \\
\hline potato radius at harvest & $r$ & $\mathrm{~m}$ & 0.04 & & 12 \\
\hline potato density & $\rho_{\mathrm{P}}$ & $\mathrm{kg} \mathrm{L}^{-1}$ & 1.1 & & 38 \\
\hline specific growth rate & $k_{\mathrm{g}}$ & day $^{-1}$ & 0.139 & & 12 \\
\hline maximum mass at harvest & $M_{\mathrm{p}}^{\max }$ & $\mathrm{kg}$ & 0.295 & estimated from the radius and density & \\
\hline initial mass (seedling) & $M_{\mathrm{p}}^{0}$ & $\mathrm{~kg}$ & 0.001 & $\begin{array}{l}\text { estimated from the specific growth rate and the maximum mass through the } \\
\text { logistic function }\end{array}$ & \\
\hline potato water content & $\theta_{\mathrm{W}}$ & $\mathrm{g} \mathrm{g}^{-1}$ & 0.778 & & 12 \\
\hline potato lipid content & & $\mathrm{g} \mathrm{g}^{-1}$ & 0.001 & & 12 \\
\hline potato carbohydrate content & & $\mathrm{g} \mathrm{g}^{-1}$ & 0.154 & & 12 \\
\hline potato tortuosity factor & $T_{\mathrm{P}}$ & & 0.72 & estimated from the water content & 12 \\
\hline \multicolumn{6}{|c|}{ Pesticide-Specific Variables } \\
\hline degradation rate in soil & $k_{\mathrm{d}, \mathrm{S}}$ & day $^{-1}$ & 0.033 & estimated from the degradation data & 36 \\
\hline degradation rate in potato & $k_{\mathrm{d}, \mathrm{P}}$ & day $^{-1}$ & 0.16 & estimated from the linear extrapolation & \\
\hline $\begin{array}{l}\text { potato tissue-water partition } \\
\text { coefficient }\end{array}$ & $K_{\mathrm{PW}}$ & $\mathrm{L} \mathrm{kg}^{-1}$ & 9.29 & estimated from the components & 12 \\
\hline $\begin{array}{l}\text { bulk soil-water partition } \\
\text { coefficient }\end{array}$ & $K_{\mathrm{SW}}$ & $\mathrm{L} \mathrm{kg}^{-1}$ & 248 & estimated & 12 \\
\hline diffusivity in water & $D_{\mathrm{W}}$ & $\mathrm{m}^{2}$ day $^{-1}$ & $5.22 \times 10^{-5}$ & estimated from molecular weight and the diffusivity of $\mathrm{O}_{2}$ in water & 39 \\
\hline
\end{tabular}

$$
\bar{C}_{\mathrm{P}}(t)=\frac{M_{\mathrm{C}}(t)}{M_{\mathrm{P}}(t)}=\left\{\begin{array}{c}
0 ; 0 \leq t<t_{\mathrm{e}} \\
4 \pi \rho_{\mathrm{P}} C F\left(\begin{array}{c}
1+\left(\frac{M_{\mathrm{p}}^{\max }-M_{\mathrm{p}}^{0}}{M_{\mathrm{p}}^{0}}\right) \exp \left(-k_{\mathrm{g}} t\right) \\
M_{p}^{\max }
\end{array}\right. \\
\int_{0}^{r_{\mathrm{p}}(t)} r^{2} C_{\mathrm{P}}\left(r, t-t_{\mathrm{e}}\right) \mathrm{d} r ; t \geq t_{\mathrm{e}}
\end{array}\right.
$$

With that, the related $\mathrm{BCF}$ at a given harvest time can be calculated as ratio of $\bar{C}_{\mathrm{P}}(t)$ and $C_{\mathrm{S}}(t)$. BCF can be interpreted as an indication of the bioaccumulation potential of chemicals into potato tubers and, hence, is directly relevant for evaluating chemical residues in potatoes that are harvested for human (or animal) consumption.

2.5. Degradation Rate of the Chemical in the Potato. The degradation process of the chemical in the potato includes microbial and chemical processes that break down the chemical bonds under certain conditions. Currently, information on chemical degradation in the potato is limited, especially for crop component-specific processes, although previous studies made efforts to derive half-lives of chemicals in crops, which yield the data for the overall dissipation process for reference conditions (i.e., $20{ }^{\circ} \mathrm{C}$ and open field) ${ }^{30,31}$ Thus, in our study, an approximate approach is applied to derive the $k_{\mathrm{d}, \mathrm{P}}$ values based on the $k_{\mathrm{d}, S}$ values of the chemicals based on the assumption that the probability of the breakdown of the chemical bond in potato tissues is linearly correlated to the related probability of the chemical breakdown in the soil at the same temperature. Thus, we applied the available reported data of the $k_{\mathrm{d}, \mathrm{P}}$ values and the $k_{\mathrm{d}, \mathrm{S}}$ values of chemicals (i.e., pesticides) to linearly extrapolate between the mean values of $k_{\mathrm{d}, \mathrm{P}}$ and $k_{\mathrm{d}, \mathrm{S}}{ }^{31}$ based on which the $k_{\mathrm{d}, \mathrm{P}}$ values for other pesticides can be derived using their available $k_{\mathrm{d}, \mathrm{S}}$ values. Table 1 summarizes the collected $k_{\mathrm{d}, \mathrm{P}}$ values of pesticides and their $k_{\mathrm{d}, \mathrm{S}}$ values based on which the linear relationship between the $k_{\mathrm{d}, \mathrm{P}}$ values derived from the means of the half-lives of the pesticides and the $k_{\mathrm{d}, S}$ values is obtained as a first proxy.

$$
k_{\mathrm{d}, \mathrm{P}}=0.29 k_{\mathrm{d}, \mathrm{S}}+0.15
$$

This approach also yields a linear approximation for the half-live of the pesticide in the potato $\left(t_{1 / 2, \mathrm{P}}\right.$, day) and the half-live of the pesticide in the soil $\left(t_{1 / 2, \mathrm{~S}}\right.$, day $)$ as follows:

$$
t_{1 / 2, \mathrm{P}}=0.12 t_{1 / 2, \mathrm{~S}}+4.03
$$

Therefore, according to eqs 12 and 13 , when $k_{\mathrm{d}, \mathrm{S}}$ is 0 (i.e., the pesticide is not degradable in the soil), the $k_{\mathrm{d}, \mathrm{P}}$ intercept denotes an intrinsic degradation rate of the pesticide inside the potato, which is caused by the cell biochemistry (e.g., enzymes) of the potato tissues. This approximation also indicates that, when $k_{\mathrm{d}, \mathrm{S}}$ is sufficiently large (i.e., $k_{\mathrm{d}, \mathrm{S}}>0.21 \mathrm{day}^{-1}$ ), the degradation process of the pesticide in the soil has a higher rate than the degradation process inside the potato, which could represent the scenarios, such as the limited cell enzyme number inside the potato or the degradation of some pesticides that is favorable to specific soil microorganisms.

\section{RESULTS AND DISCUSSION}

3.1. Chemical Distribution along the Potato Tuber Radius. The proposed dynamic model can be applied to describe the chemical diffusion into the potato tuber via two processes: (1) the outer-layer growth and (2) the equal growth of all tissue cells (or the equal growth). The outer-layer growth process describes the situation where we handle the growth of the potato by adding an outer tissue layer, such that, during the next time interval, there is a "blank" potato tissue gap between the soil and the previously chemical-contaminated potato tissue. This leads to an increasing chemical concentration gradient between the soil solution and potato tissue. Meanwhile, the equal growth process demonstrates the situation where the growth of the potato is evenly distributed across all tissue cells, such that, during the next time interval, the chemical concentration is diluted at all locations of the potato tissue as a result of the growth of the entire potato tuber. Both of these growth processes can be realized by handling the time and radius of the potato discretely in the simulation process. For the outer-layer growth process, the distribution of the pesticide concentration in the tuber at time $t$ remains constant at the beginning of the next time interval, ensuring that the growing boundary only adds to the outer layer. Conversely, for the equal growth process, we evenly interpolate the increased radius of the assumed spherical tuber during the next time interval into the whole radius of the tuber. To demonstrate the simulation process, we used the organophosphate insecticide chlorpyrifos (CAS Registry Number 2921-88-2), one of the most widely used and detected pesticides in potato fields, ${ }^{37}$ as an illustrative example, for which an initial unit concentration of chlorpyrifos in soil (i.e., $1.0 \mathrm{mg} \mathrm{kg}^{-1}$ ) was assumed after pesticide emission or soil application. Model input parameters are summarized in Table 


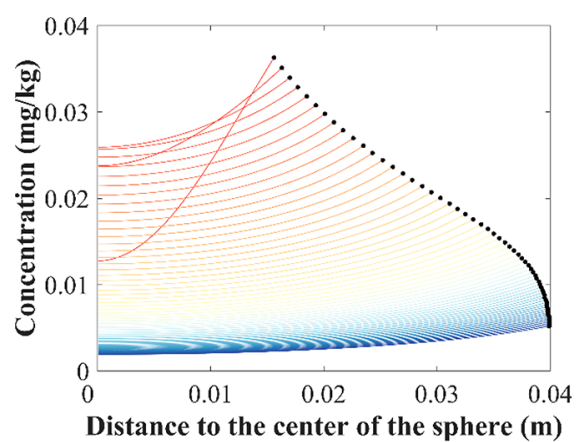

(A)

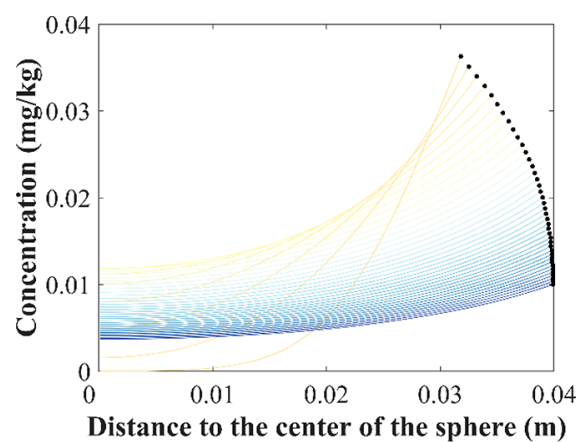

(C)

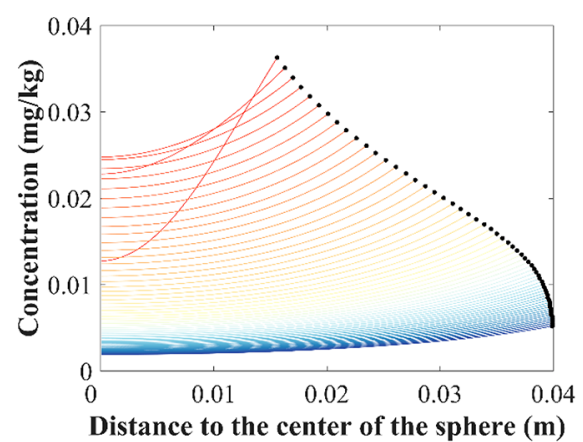

(B)

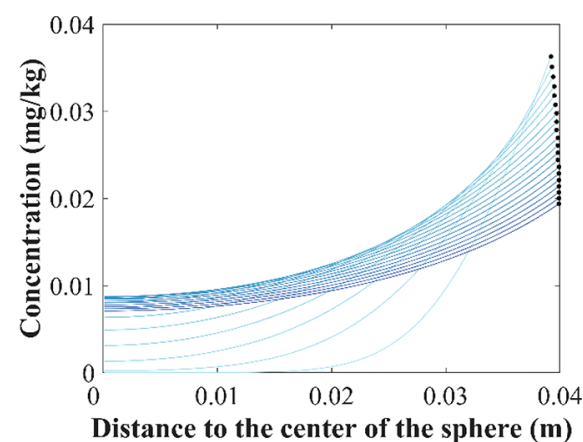

(D)

\section{Time after planting \\ (days)

$20 \quad 30 \quad 40 \quad 50$ \\ 60}

Figure 1. Simulated concentrations of chlorpyrifos distributed along the radius of the potato tuber based on a unit initial level of $1.0 \mathrm{mg} \mathrm{kg}{ }^{-1}$ of chlorpyrifos in the soil after chlorpyrifos application on different days after planting the potato according to the (A) outer-layer growth process (chlorpyrifos application at 20 days after planting the potato), (B) equal growth process (chlorpyrifos application at 20 days after planting the potato), (C) outer-layer growth process (chlorpyrifos application at 40 days after planting the potato), and (D) outer-layer growth process (chlorpyrifos application at 60 days after planting the potato). Each line indicates the distribution of chlorpyrifos concentrations along the radius of the potato at a certain time (i.e., days after plating). The lines are arranged chronically from left to right (i.e., from chlorpyrifos application to potato harvest). The black dots at the right end of the lines indicate the potato boundary layer that is in direct contact with the surrounding soil.

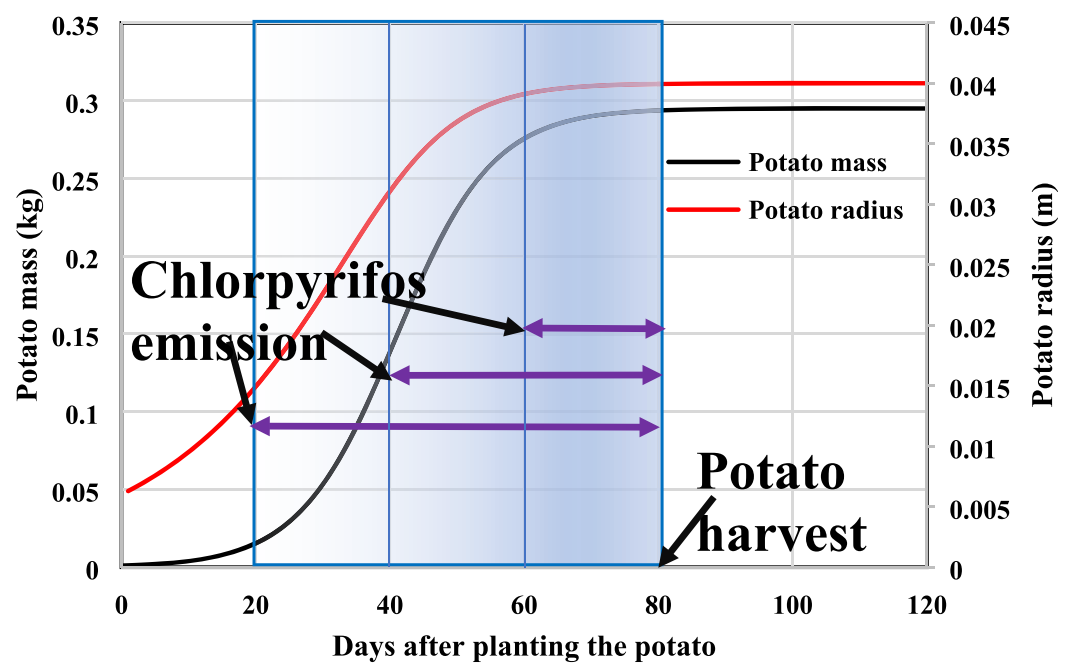

Figure 2. Potato mass and radius as functions of time (logistic growth function), with three independent emissions of chlorpyrifos at 20, 40 , and 60 days after planting the potato.

2. It was assumed that the pesticide application occurred 20, 40 , or 60 days after the potato seedling was planted and that the potato was harvested 60,40 , or 20 days after a single pesticide application.
Figure 1 illustrates the simulated chlorpyrifos levels in the potato as a function of the tuber radius and time after pesticide application. Every two lines have the same time interval of 1 day, and the length of the function line in the horizontal direction [i.e., $\left.r_{\mathrm{p}}(t)\right]$ increases with increasing time, because 
the growth of the potato follows a logistic function. These results indicate that the chlorpyrifos level distributions are nearly equal for both considered growth processes. For example, panels A and B of Figure 1 illustrate the chlorpyrifos level distributions (i.e., pesticide application at 20 days after planting the potato) for the outer-layer growth and the equal growth, respectively, where 40 days after planting the potato (i.e., 20 days after chlorpyrifos application), the simulated chlorpyrifos concentrations at the point $0.025 \mathrm{~m}$ away from the center of the potato were 0.0158 and $0.0153 \mathrm{mg} \mathrm{kg}^{-1}$ for the outer-layer growth and equal growth processes, respectively. This is because, for both growth processes, when the discrete time interval is very small (i.e., near continuous growth), the chlorpyrifos level at the soil boundary drives the overall concentration gradient along the potato radius, thereby determining the concentration distribution. In the first days after chlorpyrifos application, the chlorpyrifos concentration was lowest at the center of the potato and increased toward the outer layer of the potato as a result of the high chlorpyrifos concentration at the boundary layer. As time passes, the growth of the potato and the degradation process of chlorpyrifos inside the potato tuber reduce the chlorpyrifos concentration along the radius of the potato. In Figure 1A, because chlorpyrifos is applied 20 days after potato seeding, the logistic growth function suggests that the potato is growing much faster than it was at the stage of sprout development, which quickly dilutes the chlorpyrifos concentrations along the radius of the potato (see Figure 2). This enhanced dilution phenomenon was identified by the relatively large spaces between the two neighboring lines in Figure 1A compared to Figure 1D (i.e., pesticide application at 60 days after planting the potato), which indicate a rapidly decreasing chlorpyrifos concentration along the radius of the potato. When the potato reaches its maturation state (i.e., 60-80 days after seeding), both the absolute growth rate of the potato and the absolute degradation rate of chlorpyrifos in the soil (i.e., pseudo firstorder kinetics ${ }^{31}$ ) are slow, resulting in a diminishing diffusion flux of chlorpyrifos toward the center of the potato. It was observed that the concentration-distribution lines near the maturation stage were becoming nearer, which is because the dilution process of the absolute growth rate of the potato and the diffusion process of the absolute degradation rate of chlorpyrifos in the soil are limited.

3.2. Chemical Uptake Processes into Potato Tuber. Because it is necessary to understand the overall uptake of pesticides into harvested potato components rather than the distribution of pesticides along the tuber radius, we integrated $C_{\mathrm{P}}(r, t)$ along the tuber radius to obtain the pesticide concentration in the potato as a function of time. The dynamic model revealed a different distribution trend compared to the classic diffusion model. Figure 3 illustrates simulated $\bar{C}_{\mathrm{P}}(t)$ and $C_{\mathrm{P}}^{\mathrm{c}}(t)$ of chlorpyrifos in the potato during the time between pesticide application and potato harvest for the dynamic and classic models, respectively. In Figure 3A (i.e., chlorpyrifos application at 20 days after plating the potato), the dynamic model shows that $\bar{C}_{\mathrm{P}}(t)$ of chlorpyrifos reached a maximum value of $0.0312 \mathrm{mg} / \mathrm{kg}$ shortly after pesticide application (i.e., 22 days) and decreased with increasing time. Conversely, for the classic model, $C_{\mathrm{P}}^{\mathrm{c}}(t)$ of chlorpyrifos increased slowly with increasing time, reached a maximum value at approximately 8 days after pesticide application, and then quickly decreased. This inconsistency originated from the base perspective of the models. The dynamic model tracks the

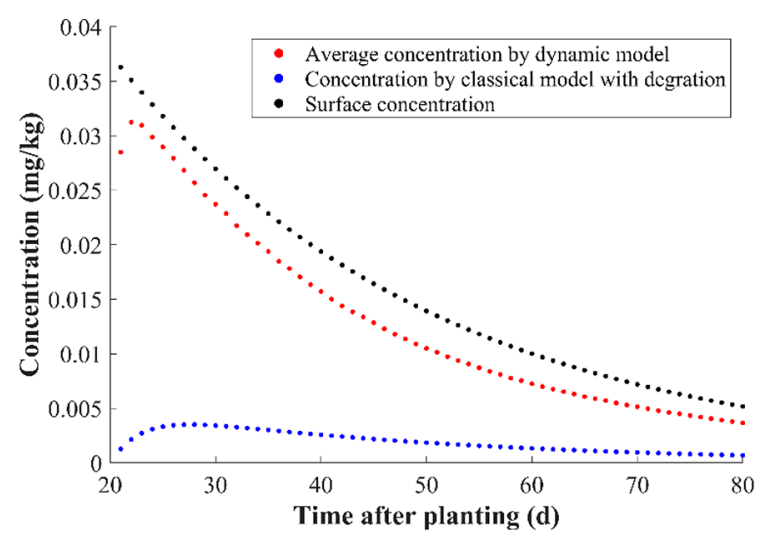

(A)

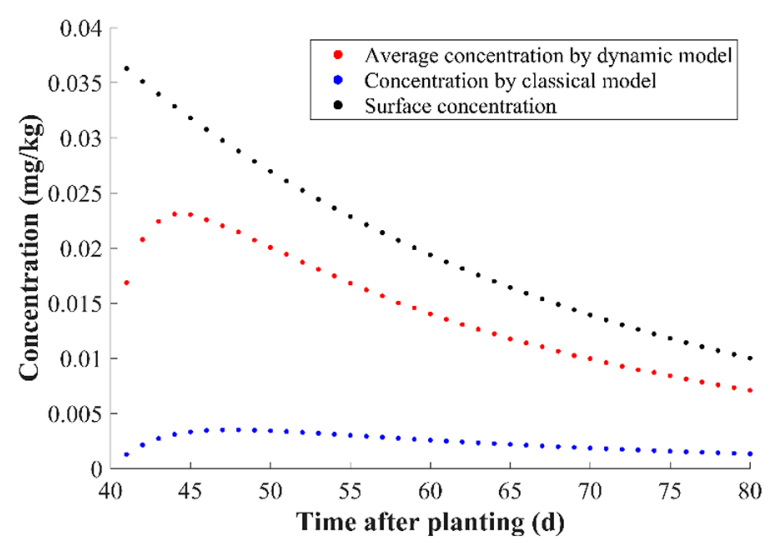

(B)

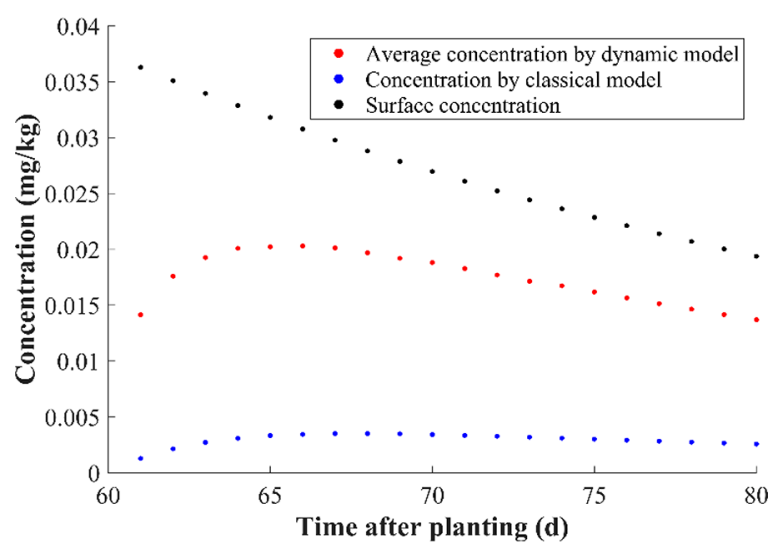

(C)

Figure 3. Simulated average concentrations of chlorpyrifos in the potato based on a unit initial level of $1.0 \mathrm{mg} \mathrm{kg}{ }^{-1}$ of chlorpyrifos in the soil using both the dynamic and classic models: chlorpyrifos application at (A) 20, (B) 40, and (C) 60 days after planting the potato.

uptake process of chlorpyrifos starting from a very small potato, which has a small radius and low initial mass, which significantly increases the diffusion flux and $\bar{C}_{\mathrm{P}}(t)$ of chlorpyrifos, respectively (see Figure 4A). Also, Figure 4A shows that, when the potato enters the fast-growing stage of the logistic growth function (i.e., 20 days after seeding), the magnified dilution effect of chlorpyrifos enhances the elimination process of chlorpyrifos by the potato, leading to rapidly decreasing $\bar{C}_{\mathrm{P}}(t)$ immediately after pesticide applica- 


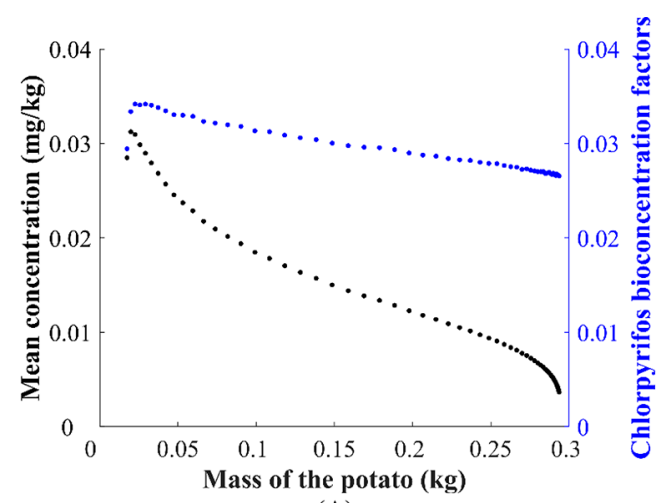

(A)

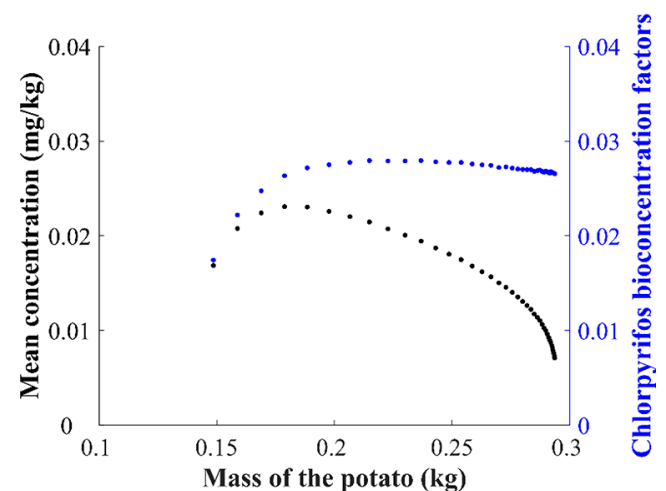

(B)

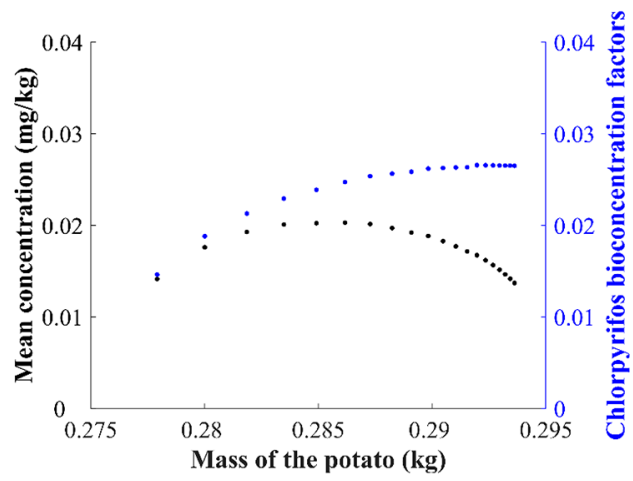

(C)

Figure 4. Simulated average concentrations of chlorpyrifos and bioconcentration factors in the potato plotted against the mass of the potato based on a unit initial level of $1.0 \mathrm{mg} \mathrm{kg}^{-1}$ of chlorpyrifos in the soil using both the dynamic and classic models: chlorpyrifos application at (A) 20, (B) 40, and (C) 60 days after planting the potato.

tion. As time passes, the absolute growth rate of the potato reaches a steady state (i.e., approximately 40 days after seeding), which stabilizes the dilution effect of chlorpyrifos and further weakens the overall elimination process, causing the $\bar{C}_{\mathrm{P}}(t)$ curve to become a convex downward (or concave upward) function with an inflection point at approximately 25 days after seeding. When the potato enters the maturation stage (i.e., 60 days after seeding), where its mass reaches a maximum value and its absolute growth rate nears 0 , the overall elimination process of chlorpyrifos is mainly determined by the concentration gradient between the inner part and boundary layer and the degradation process inside the potato tuber. Thus, the formation of the convex downward function after the maximum concentration was caused by the logistic growth function of the potato that was transferred to a sigmoid moving boundary. On the other hand, when the chlorpyrifos application happens 40 or 60 days after planting the potato, the shapes of the dynamic model are more similar to the shape of the classic model (see panels B and C of Figure 3 ), which is due the fact that the mass of the potato has already increased substantially (see panels B and C of Figure 4). Overall, the $\bar{C}_{\mathrm{P}}(t)$ values simulated using the dynamic model are much higher than those of the classical model, which is due to the expanding radius of the potato and the radial distribution of the chlorpyrifos concentrations used in the dynamic model that drive larger concentration gradients between the inner part and the boundary layer, resulting in higher average chlorpyrifos concentrations.

3.3. Bioconcentration Factors Based on Dynamic and Classic Diffusion Models. As a relevant input metric for human exposure and health risk assessments associated with pesticide residues in harvested food crops, we also estimated the $\mathrm{BCF}$ of chlorpyrifos in potato tubers as a function of time using the dynamic and classic models. Figure 5 illustrates the BCF of chlorpyrifos in a potato as a function of time between chlorpyrifos application (i.e., 20, 40, or 60 days after seeding) and potato tuber harvest (i.e., 80 days after seeding). Similar to $\bar{C}_{\mathrm{P}}(t)$ and $C_{\mathrm{P}}^{\mathrm{c}}(t)$, the simulated BCF values of chlorpyrifos in the potato using the dynamic model show a quick jump when the chlorpyrifos application occurs 20 days after seeding, followed by a rapid decrease as time passes (see Figure 5A). Further, when the minimum preharvest interval (PHI) becomes smaller (i.e., 40 and 60 days after seeding), the shapes of the dynamic model are more similar to the classical model. Overall, the simulated BCFs of chlorpyrifos using the dynamic model are much higher than the BCF of the classical model. For example, at harvest, the simulated BCFs of chlorpyrifos using the dynamic model are 0.0266, 0.0266, and 0.0265 for the chlorpyrifos application at 20,40, and 60 days after planting the potato, respectively, which are closer to the experimental observation of 0.038 (i.e., 0.19 and $5.0 \mathrm{mg}$ $\mathrm{kg}^{-1}$ of the chlorpyrifos concentrations in the potato and soil at 91 days after plating the potato). ${ }^{40}$ Rigueira et al. ${ }^{40}$ planted the pesticide-free potatoes purchased from a local market in containers with the chlorpyrifos-treated soils (Oxisol redyellow), while the classical model at harvest yields a simulated BCF value of 0.0050 , which is much lower than the observation by Rigueira et al. ${ }^{40}$ However, Juraske et al. ${ }^{13}$ reported a measured $\mathrm{BCF}$ of chlorpyrifos in the potato of 0.006, which matches the classical model better than the dynamic model, but it is noted that this measured BCF is based on the overall averages of the chlorpyrifos concentration in the potato and the soil rather than the collected data at harvest. Thus, from the perspective of health risk assessment, the dynamic model seems to be more protective than the classical model, but more experimental or field data are required to further evaluate both models. In this study, the use of chlorpyrifos is to illustrate the model application and to validate our simulated results. For other pesticides, users can apply our model using the code provided in the Supporting Information with pesticide physiochemical properties. For other types of potatoes, such as sweet potatoes and white potatoes, users can change the water, lipid, and carbohydrate contents of the tuber tissues to calculate the new potato-water partition coefficients of pesticides (methods and references provided in Table 2). 


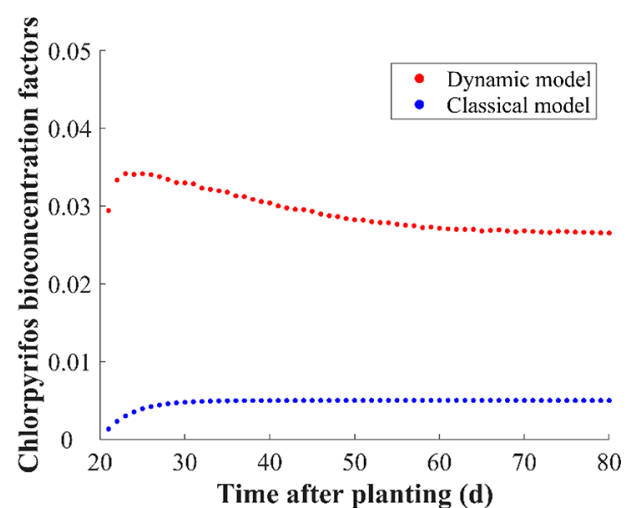

(A)

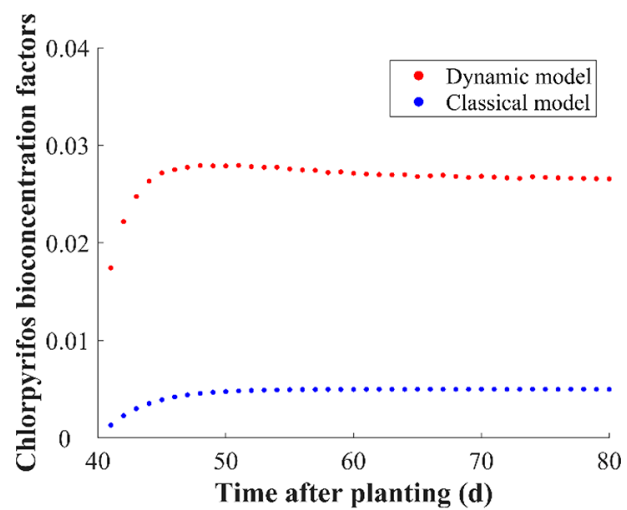

(B)

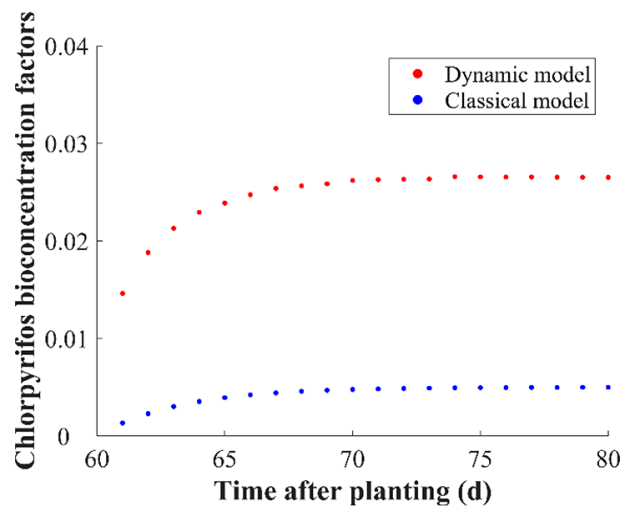

(C)

Figure 5. Simulated chlorpyrifos BCFs in the potato tuber as a function of time between chlorpyrifos application and tuber harvest for the dynamic and classic diffusion models: chlorpyrifos application at (A) 20, (B) 40, and (C) 60 days after planting the potato.

3.4. Model Implications, Limitations, and Recommendations for Future Studies. Although the simulated chlorpyrifos BCF values and average concentrations at the time of considered potato harvest using the dynamic model seem to be closer to the experimental data than those from the classical model, further field or experimental studies must be performed to evaluate the model. For example, we estimated the $k_{\mathrm{d}, \mathrm{P}}$ value of chlorpyrifos inside the potato tuber using limited input information, which could yield some levels of inaccuracy. Some field studies have evaluated the chlorpyrifos concentrations in potatoes, but they mainly focused on potatoes during the maturation stage. For example, Juraske et al. ${ }^{13}$ conducted modeling and experimental studies for uptake of chlorpyrifos into potatoes. In their study, potato samples were collected for chlorpyrifos concentration measurements at 100 days after the potatoes were planted, at which time the potatoes were already in the maturation stage. At this point, only the chlorpyrifos concentration gradient between the potato and the boundary layer determines the diffusion flux of chlorpyrifos into the potato, which is explained by our dynamic model because the moving boundary is a fixed value instead of a sigmoid growing boundary. There is a lack of additional experimental data assessing the profile of chlorpyrifos and other pesticide concentrations during all growth stages of potatoes. This aspect is relevant for the following reasons: (1) During the early growth stage of tuber plants, plant tissues are under cellular differentiation, meaning that the uptake of a certain level of pesticide residues may damage the plant tissues. ${ }^{41}$ (2) In the present study, the peel effect on the uptake of pesticide residues was not specifically considered. A potato peel has a different chemical composition and physiological structure than the potato tuber tissue, which could affect the diffusion process of pesticides. Because the peel is formed in the early growing stage, it may play a significant role in the uptake of pesticides by potatoes. For example, if the peel acts as a barrier to the transport of pesticides through the boundary layer, the uptake process of pesticides may be impeded, implying that adding a peel compartment to the dynamic model during the sprout development stage could better reflect pesticide distribution in potato tubers. (3) Studies have shown that some insects and bugs can culture in sprouting potatoes. ${ }^{42,43}$ Therefore, predicting the concentration of pesticides in early growth stages may help to evaluate the overall potato health. However, because there is limited information regarding pesticide residues in sprouting potatoes, we suggest that, in the future, field studies are conducted to evaluate pesticide concentrations throughout the growth of the potato. We further note that the lipid and carbohydrate contents of the tuber could vary across growth stages of the potato, which may affect the partition coefficients of the pesticides, which may affect uptake rates. As a result of current data limitation, we applied constant values for lipid and carbohydrate contents of the tuber, in line with previous studies. (4) Most importantly, pesticides may be applied at all growth stages of potato and other crops, for which residue profiles from usually more than a single pesticide applied in a single application might become relevant for both the plant health as well as subsequent human exposure and related potential health risks from consuming harvested crop components that contain pesticide residues.

In the present study, we introduced a moving-boundary model to evaluate the uptake process of pesticides into potato tubers based on a logistic potato growth function. This model dynamically describes the distribution of pesticides along the radius of the potato. Simulated results (e.g., BCF and average concentration) of the dynamic model were higher than those of a classic diffusion model and closer to experimental results. This indicates that the dynamic model could be more protective in the context of human risk assessment when estimating the results at certain harvest times. The chlorpyrifos application simulations using the dynamic model revealed a different chlorpyrifos uptake process by the potato, exhibiting a quick and big jump of the chlorpyrifos concentration in the potato, especially when chlorpyrifos is applied at the sprouting or growing stage of the potato. This uptake process was caused by the sigmoid growing boundary layer between the potato tissues and the surrounding soil. Although experimental or field data are required to further evaluate our dynamic model, it 
provides a new understanding of the pesticide uptake process by tuber plants. This may have implications for human exposure and health risk assessment for pesticides applied at different tuber growth stages as well as for identifying optimal pesticide application times with respect to plant health.

\section{ASSOCIATED CONTENT}

\section{SI Supporting Information}

The Supporting Information is available free of charge at https://pubs.acs.org/doi/10.1021/acs.jafc.1c00151.

MATLAB code (PDF)

\section{AUTHOR INFORMATION}

\section{Corresponding Author}

Zijian Li - School of Public Health (Shenzhen), Sun Yat-sen University, Guangzhou, Guangdong 510275, People's Republic of China; (1) orcid.org/0000-0002-9291-5966; Phone: +86-136-4430-2865; Email: lizijian3@ mail.sysu.edu.cn

\section{Authors}

Shenglan Xiao - School of Public Health (Shenzhen), Sun Yat-sen University, Guangzhou, Guangdong 510275, People's Republic of China

Yishu Gong - Department of Mathematics, Duke University, Durham, North Carolina 27708, United States

Peter Fantke - Quantitative Sustainability Assessment, Department of Technology, Management and Economics, Technical University of Denmark, 2800 Kongens Lyngby, Denmark; 이이.orcid.o000-0001-7148-6982

Complete contact information is available at: https://pubs.acs.org/10.1021/acs.jafc.1c00151

\section{Funding}

This work was financially supported by the Sun Yat-sen University (Grant 58000-18841211), the SPRINT Project (Grant Agreement 862568) funded by the European Commission through Horizon 2020, and the FNS-Cloud Project (Grant Agreement 863059) funded by the European Commission through Horizon 2020.

\section{Notes}

The authors declare no competing financial interest.

\section{REFERENCES}

(1) Leong, W. H.; Teh, S. Y.; Hossain, M. M.; Nadarajaw, T.; Zabidi-Hussin, Z.; Chin, S. Y.; Lai, K. S.; Lim, S. H. E. Application, Monitoring and Adverse Effects in Pesticide Use: The Importance of Reinforcement of Good Agricultural Practices (GAPs). J. Environ. Manage. 2020, 260, 109987.

(2) Foong, S. Y.; Ma, N. L.; Lam, S. S.; Peng, W.; Low, F.; Lee, B. H. K.; Alstrup, A. K. O.; Sonne, C. A Recent Global Review of Hazardous Chlorpyrifos Pesticide in Fruit and Vegetables: Prevalence, Remediation and Actions Needed. J. Hazard. Mater. 2020, 400, 123006.

(3) Gentil, C.; Fantke, P.; Mottes, C.; Basset-Mens, C. Challenges and Ways Forward in Pesticide Emission and Toxicity Characterization Modeling for Tropical Conditions. Int. J. Life Cycle Assess. 2020, 25, 1290-1306.

(4) Fantke, P.; Jolliet, O. Life Cycle Human Health Impacts of 875 Pesticides. Int. J. Life Cycle Assess. 2016, 21, 722-733.

(5) Fantke, P.; Friedrich, R.; Jolliet, O. Health Impact and Damage Cost Assessment of Pesticides in Europe. Environ. Int. 2012, 49, 917.
(6) Hamilton, D.; Ambrus, Á.; Dieterle, R.; Felsot, A.; Harris, C.; Petersen, B.; Racke, K.; Wong, S. S.; Gonzalez, R.; Tanaka, K.; Earl, M.; Roberts, G.; Bhula, R. Pesticide Residues in Food-Acute Dietary Exposure. Pest Manage. Sci. 2004, 60, 311-339.

(7) Mansour, S. A. Pesticide Exposure-Egyptian Scene. Toxicology 2004, 198, 91-115.

(8) Trapp, S.; Matthies, M. Generic One-Compartment Model for Uptake of Organic Chemicals by Foliar Vegetation. Environ. Sci. Technol. 1995, 29, 2333-2338.

(9) Li, Z. A New Pseudo-Partition Coefficient Based on a WeatherAdjusted Multicomponent Model for Mushroom Uptake of Pesticides from Soil. Environ. Pollut. 2020, 256, 113372.

(10) Li, Z. Spatiotemporal Pattern Models for Bioaccumulation of Pesticides in Common Herbaceous and Woody Plants. J. Environ. Manage. 2020, 276, 111334.

(11) Juraske, R.; Antón, A.; Castells, F.; Huijbregts, M. A. J. Human Intake Fractions of Pesticides via Greenhouse Tomato Consumption: Comparing Model Estimates with Measurements for Captan. Chemosphere 2007, 67, 1102-1107.

(12) Trapp, S.; Cammarano, A.; Capri, E.; Reichenberg, F.; Mayer, P. Diffusion of PAH in Potato and Carrot Slices and Application for a Potato Model. Environ. Sci. Technol. 2007, 41, 3103-3108.

(13) Juraske, R.; Mosquera Vivas, C. S.; Erazo Velásquez, A.; García Santos, G.; Berdugo Moreno, M. B.; Diaz Gomez, J.; Binder, C. R.; Hellweg, S.; Guerrero Dallos, J. A. Pesticide Uptake in Potatoes: Model and Field Experiments. Environ. Sci. Technol. 2011, 45, 651657.

(14) Fantke, P.; Charles, R.; de Alencastro, L. F.; Friedrich, R.; Jolliet, O. Plant Uptake of Pesticides and Human Health: Dynamic Modeling of Residues in Wheat and Ingestion Intake. Chemosphere 2011, 85, 1639-1647.

(15) Fantke, P.; Wieland, P.; Wannaz, C.; Friedrich, R.; Jolliet, O. Dynamics of Pesticide Uptake into Plants: From System Functioning to Parsimonious Modeling. Environ. Model. Softw. 2013, 40, 316-324.

(16) Gentil, C.; Basset-Mens, C.; Manteaux, S.; Mottes, C.; Maillard, E.; Biard, Y.; Fantke, P. Coupling Pesticide Emission and Toxicity Characterization Models for LCA: Application to Open-Field Tomato Production in Martinique. J. Cleaner Prod. 2020, 277, 124099.

(17) Pang, N.; Fan, X.; Fantke, P.; Zhao, S.; Hu, J. Dynamics and Dietary Risk Assessment of Thiamethoxam in Wheat, Lettuce and Tomato Using Field Experiments and Computational Simulation. Environ. Pollut. 2020, 256, 113285.

(18) Feng, X.; Wang, K.; Pan, L.; Xu, T.; Zhang, H.; Fantke, P. Measured and Modeled Residue Dynamics of Famoxadone and Oxathiapiprolin in Tomato Fields. J. Agric. Food Chem. 2018, 66, 8489-8495.

(19) Wijesinha-Bettoni, R; Mouillé, B. The Contribution of Potatoes to Global Food Security, Nutrition and Healthy Diets. Am. J. Potato Res. 2019, 96, 139-149.

(20) Narenderan, S. T.; Meyyanathan, S. N. Sample Treatment and Determination of Pesticide Residues in Potato Matrices: A Review. Potato Res. 2019, 62, 47-67.

(21) Nzediegwu, C.; Prasher, S.; Elsayed, E.; Dhiman, J.; Mawof, A.; Patel, R. Effect of Biochar on Heavy Metal Accumulation in Potatoes from Wastewater Irrigation. J. Environ. Manage. 2019, 232, 153-164.

(22) Hwang, J. I.; Zimmerman, A. R.; Kim, J. E. Bioconcentration Factor-Based Management of Soil Pesticide Residues: Endosulfan Uptake by Carrot and Potato Plants. Sci. Total Environ. 2018, 627, 514-522.

(23) Paraíba, L. C.; Kataguiri, K. Model Approach for Estimating Potato Pesticide Bioconcentration Factor. Chemosphere 2008, 73, $1247-1252$

(24) Fantke, P.; Wieland, P.; Juraske, R.; Shaddick, G.; Itoiz, E. S.; Friedrich, R.; Jolliet, O. Parameterization Models for Pesticide Exposure via Crop Consumption. Environ. Sci. Technol. 2012, 46, 12864-12872.

(25) Fantke, P.; Arnot, J. A.; Doucette, W. J. Improving Plant Bioaccumulation Science through Consistent Reporting of Experimental Data. J. Environ. Manage. 2016, 181, 374-384. 
(26) Doucette, W. J.; Shunthirasingham, C.; Dettenmaier, E. M.; Zaleski, R. T.; Fantke, P.; Arnot, J. A. A Review of Measured Bioaccumulation Data on Terrestrial Plants for Organic Chemicals: Metrics, Variability, and the Need for Standardized Measurement Protocols. Environ. Toxicol. Chem. 2018, 37, 21-33.

(27) Satchivi, N. M.; Stoller, E. W.; Wax, L. M.; Briskin, D. P. A Nonlinear Dynamic Simulation Model for Xenobiotic Transport and Whole Plant Allocation Following Foliar Application I. Conceptual Foundation for Model Development. Pestic. Biochem. Physiol. 2000, $68,67-84$.

(28) Jacobsen, R. E.; Fantke, P.; Trapp, S. Analysing Half-Lives for Pesticide Dissipation in Plants. SAR QSAR Environ. Res. 2015, 26, 325-342.

(29) Rein, A.; Legind, C. N.; Trapp, S. New Concepts for Dynamic Plant Uptake Models. SAR QSAR Environ. Res. 2011, 22, 191-215.

(30) Fantke, P.; Gillespie, B. W.; Juraske, R.; Jolliet, O. Estimating Half-Lives for Pesticide Dissipation from Plants. Environ. Sci. Technol. 2014, 48, 8588-8602.

(31) Fantke, P.; Juraske, R. Variability of Pesticide Dissipation HalfLives in Plants. Environ. Sci. Technol. 2013, 47, 3548-3562.

(32) Stuart, I. A.; Ansell, R. O.; MacLachlan, J.; Bather, P. A. Surface Partitioning Studies of N-Methylcarbamate-Treated Post-Harvest Crops Using SFE-HPLC-Postcolumn Reaction-Fluorescence. Analyst 1999, 124, 275-280.

(33) Roy, S.; Alam, S.; Chowdhury, A. Dissipation of Curzate (Cymoxanil 8\% + Mancozeb 64\%) in Potato Tuber and Cropped Soil. Pestic. Res. J. 2010, 22, 5-9.

(34) Qin, D.; Xu, Y.; Huang, Y.; Sun, Y.; He, L. Residue Dynamics of Mancozeb and Its Metabolite Ethylenethiourea in Potato and Soil. Agrochemicals 2008, 27, 305-309.

(35) Aktar, M. W.; Paramasivam, M.; Sengnpta, D. Persistence and Dissipation of Propineb-A Dithiocarbamate Fungicide in Potato under East-Indian Climatic Conditions. Kasetsart J. - Nat. Sci. 2009, $43,50-55$.

(36) Lewis, K. A.; Tzilivakis, J.; Warner, D. J.; Green, A. An International Database for Pesticide Risk Assessments and Management. Hum. Ecol. Risk Assess. 2016, 22, 1050-1064.

(37) Das, S.; Hageman, K. J.; Taylor, M.; Michelsen-Heath, S.; Stewart, I. Fate of the Organophosphate Insecticide, Chlorpyrifos, in Leaves, Soil, and Air Following Application. Chemosphere 2020, 243, 125194.

(38) Li, Z. A Coupled ODE-Diffusion Modeling Framework for Removing Organic Contaminants in Crops Using a Simple Household Method. Environ. Pollut. 2020, 265, 115071.

(39) Trapp, S. Fruit Tree Model for Uptake of Organic Compounds from Soil and Air. SAR QSAR Environ. Res. 2007, 18, 367-387.

(40) Rigueira, L. M. B.; Ribeiro, K. L.; de Queiroz, M. E. L. R.; Neves, A. A.; Zambolim, L.; Oliveira, R. M. Determination of Chlorpyrifos and Thiamethoxam in Potato Tuber (Solanum tuberosum L.) and Soil of Brazil Using Solid-Liquid Extraction with Low Temperature Partitioning (SLE/LTP). J. Braz. Chem. Soc. 2013, 24, 2042-2049.

(41) Shakir, S. K.; Irfan, S.; Akhtar, B.; Rehman, S. ur; Daud, M. K.; Taimur, N.; Azizullah, A. Pesticide-Induced Oxidative Stress and Antioxidant Responses in Tomato (Solanum Lycopersicum) Seedlings. Ecotoxicology 2018, 27, 919-935.

(42) Michaud, D.; Nguyen-Quoc, B.; Bernier-Vadnais, N.; Faye, L.; Yelle, S. Cysteine Proteinase Forms in Sprouting Potato Tuber. Physiol. Plant. 1994, 90, 497-503.

(43) Eaton, T. E.; Azad, A. K.; Kabir, H.; Siddiq, A. B. Evaluation of Six Modern Varieties of Potatoes for Yield, Plant Growth Parameters and Resistance to Insects and Diseases. Agric. Sci. 2017, 8, 13151326. 